
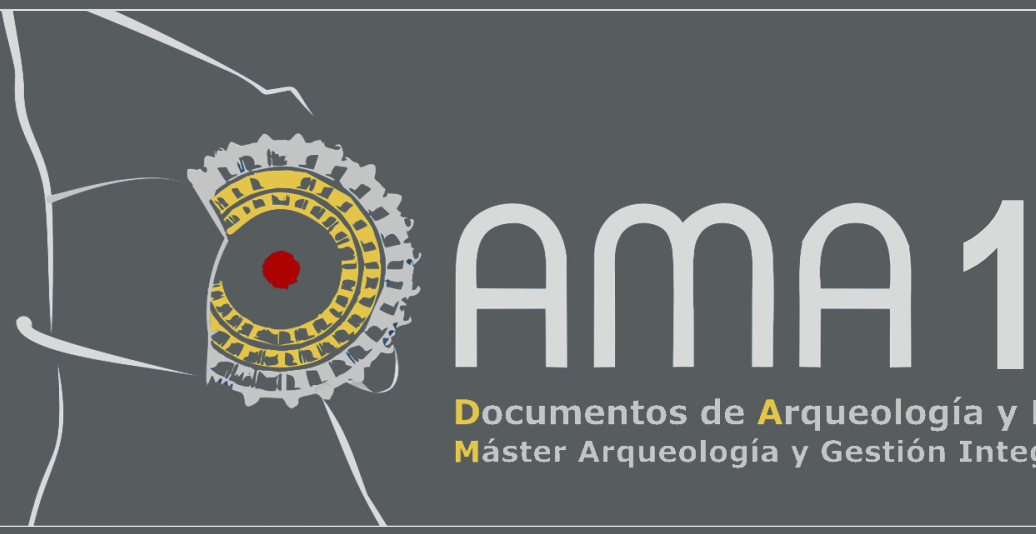

Documentos de Arqueología y Patrimonio Histórico

Máster Arqueología y Gestión Integral del Patrimonio de la Universidad de Alicante

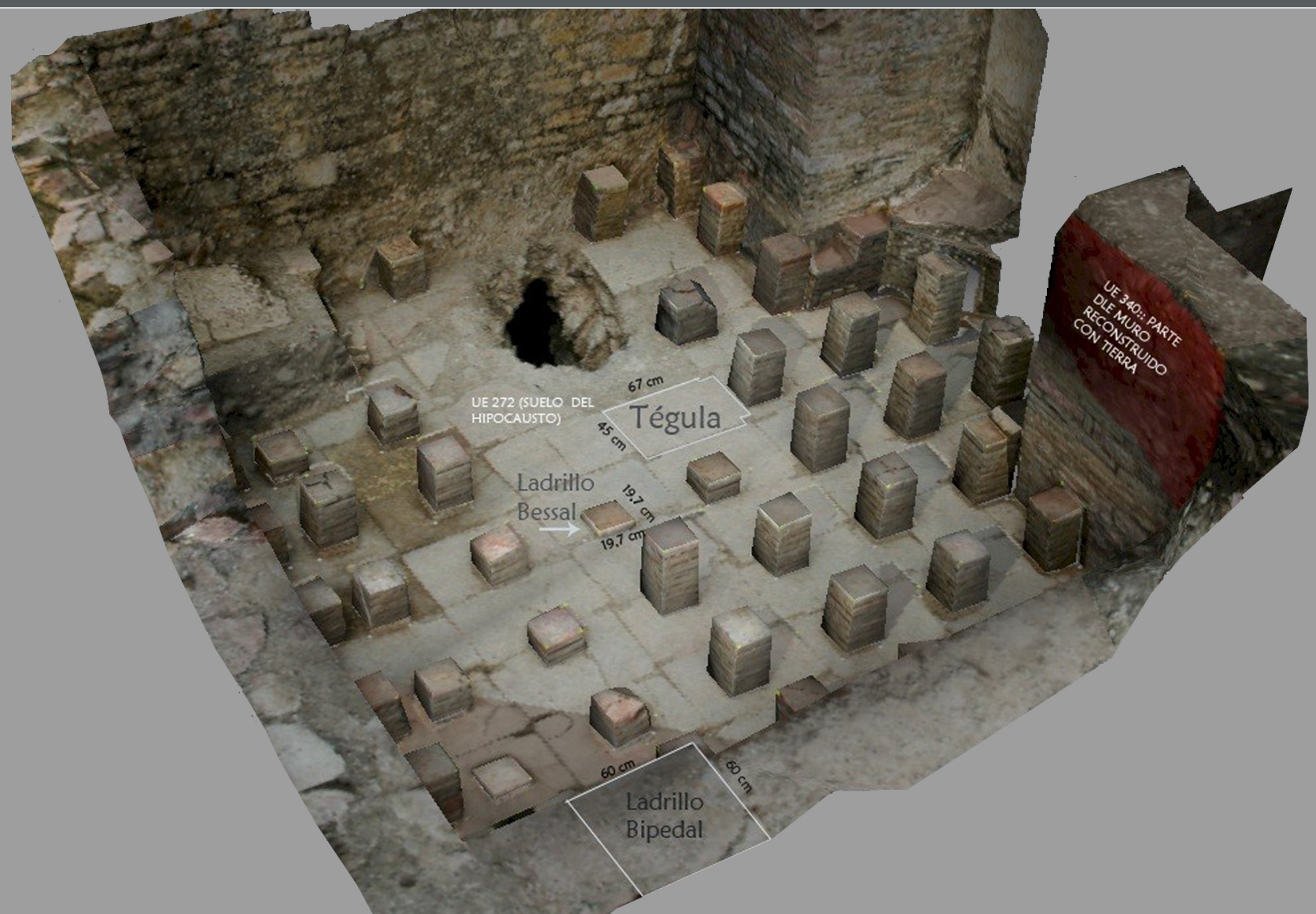

Documentos de Arqueología y Patrimonio Histórico Revista del Máster Universitario en Arqueología Profesional y Gestión integral del Patrimonio 



\section{DAMA 1}

\section{6}

DOCUMENTOS DE ARQUEOLOGÍA Y PATRIMONIO HISTÓRICO DEL MÁSTER UNIVERSITARIO EN ARQUEOLOGÍA PROFESIONAL Y GESTIÓN INTEGRAL DEL PATRIMONIO DE LA UNIVERSIDAD DE ALICANTE 


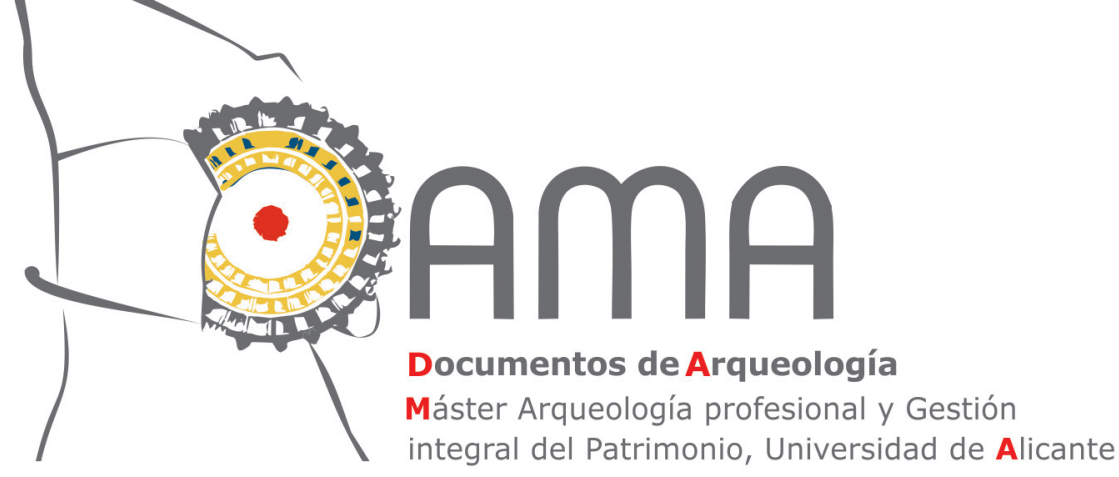

La revista electrónica DAMA. Documentos de Arqueología y Patrimonio Histórico surge como servicio para todos aquellos alumnos del Máster en Arqueología Profesional y Gestión Integral del Patrimonio de la Universidad de Alicante que se están iniciando en la investigación y cuya primera aportación a nuestra disciplina suele ser su Trabajo de Fin de Máster (TFM). Estos proyectos en muchos casos representan casi todo un curso de trabajo y esfuerzo, y con frecuencia quedan inéditos.

El objetivo de esta revista es ofrecer un medio que facilite la publicación de los resultados de sus TFM. La edición se presenta en versión digital y cuenta con su correspondiente ISSN. Se publica de forma anual en el sitio web de la Universidad de Alicante (http://web.ua.es/es/dama/) y en su repositorio (RUA). Los artículos publicados son descargables en formato PDF.

\section{Consejo de Redacción}

Directores (Coordinadores del Máster)

Carolina Doménech Belda

Fernando Prados Martínez

\section{Secretaria de Edición}

Julia Sarabia Bautista

\section{Vocales}

Los miembros de la Comisión Académica del Máster Universitario en Arqueología Profesional y Gestión del Patrimonio (http://dprha.ua.es/es/magip/comision-academica.html)

\section{Edita}

Máster Universitario en Arqueología Profesional y Gestión Integral del Patrimonio Departamento de Prehistoria, Arqueología, Historia Antigua, Filología Griega y Filología Latina

Facultad de Filosofía y Letras II

Universidad de Alicante

Ctra San Vicente del Raspeig s/n

E-03690 San Vicente del Raspeig (Alicante)

Web:http://dprha.ua.es

Teléfono: (+34) 965903663

Fax: (+34) 965903823

E-mail: revista.dama@ua.es

\section{ISSN}

$2530-2345$

\section{Portada}

Modelo fotogramétrico de un hypocaustum romano realizado por Ana Charquero 
EDITORIAL

Coordinación del máster

ENTREVISTA A SOLVEIG NORDSTRÖM: UNA MIRADA HACIA EL PASADO DE LA ESCUERA

Raúl Berenguer González ..

\section{ARQUEOLOGÍA Y MÉTODO}

EL ESTUDIO DE LOS MATERIALES CONSTRUCTIVOS DE TIERRA DEL CABEZO DEL POLOVAR (VILLENA, ALICANTE): APORTACIÓN A LAS FORMAS CONSTRUCTIVAS DE DOS PEQUEÑAS EDIFICACIONES CAMPESINAS DE LA EDAD DEL BRONCE EN EL LEVANTE PENINSULAR

María Pastor Quiles

VIVIENDAS POSTALAYÓTICAS: UNA APROXIMACIÓN A LOS ESPACIOS DOMÉSTICOS EN EL ARCHIPIÉLAGO BALEAR (550-123 ANE)

Octavio Torres Gomáriz

LAS FLOTAS DE GUARNICIÓN ROMANA EN LAS COSTAS DE HISPANIA A PARTIR DE LAS FUENTES EPIGRÁFICAS

Sergio Lledó Ramírez

UNA APROXIMACIÓN A LA RECONSTRUCCIÓN DEL PAISAJE HISTÓRICO: EL PROYECTO L'ALMISSERÀ Diana López Arroyo

NUEVAS PERSPECTIVAS PARA EL ESTUDIO ARQUEOLÓGICO DEL POBLAMIENTO RURAL MEDIEVAL EN ASPE (ALICANTE): HUERTAS Y ALQUERÍAS JUNTO AL RÍO TARAFA

Felipe Mejías López

ARQUEOLOGÍA DE LAS GUERRAS CARLISTAS

Iván Roldán Vergarachea

LA CERÁMICA DE USO ARQUITECTÓNICO EN NOVELDA: LA AZULEJERÍA DE FINALES DEL SIGLO XIX Y PRINCIPIOS DEL XX

Natalia Sala Pérez

PRÁCTICA Y USOS DE LA FOTOGRAMETRÍA DIGITAL EN ARQUEOLOGÍA

Ana $M^{a}$ Charquero Ballester.

\section{GESTIÓN Y PUESTA EN VALOR DEL PATRIMONIO}

ARQUEÓLOGOS CON DISCAPACIDAD. ARQUEOLOGÍA INCLUSIVA

Ana Samaniego Espinosa

"LES COVES DELS PESCADORS DE EL CAMPELLO": PROPUESTA DE RECUPERACIÓN, PUESTA EN VALOR Y USO PÚBLICO DE UN PATRIMONIO OLVIDADO

Ana Isabel Castro Carbonell .

LA COLONIA DE SANTA EULALIA. ESTUDIO Y PROPUESTA DE RECUPERACIÓN

Héctor de Arriba González

PROYECTO DE PUESTA EN VALOR DE LOS RESTOS DE LA GUERRA CIVIL EN LA CIUDAD DE ALICANTE

Leticia Victoria González Chouciño

ANTEPROYECTO MUSEOGRÁFICO DEL MUSEO DE HISTORIA DE SAX

Alberto Ochoa García

EL CONGRESO DE MÁSTER: UNA PROPUESTA DIDÁCTICA DEL MÁSTER DE ARQUEOLOGÍA DE LA UNIVERSIDAD DE ALICANTE

Ignasi Grau Mira, Sonia Gutiérrez Lloret, Carolina Doménech Belda, Julia Sarabia Bautista 



\title{
LAS FLOTAS DE GUARNICIÓN ROMANA EN LAS COSTAS DE HISPANIA A PARTIR DE LAS FUENTES EPIGRÁFICAS
}

\author{
Sergio Lledó Ramírez
}

\section{RESUMEN}

El objetivo de este trabajo es reunir en un único texto las principales fuentes existentes sobre la flota romana en las costas de Hispania y, en la medida de lo posible, realizar un análisis crítico que ayude a clarificar el número de flotas de guarnición destinadas en nuestras costas. Se prestará para ello atención a las fuentes epigráficas existentes, poniéndolas en relación a las fuentes clásicas y actuales, encaminándose de este modo hacia la elaboración de una tesis que encajada en un marco más amplio permita comprender mejor el método de control y dominación romano en el mediterráneo occidental.

Palabras clave: Hispania, ejército, flota, ora marítima, guarnición, costas

\begin{abstract}
The aim of this study is to gather in a single text the main existing sources on the roman fleet of the coast of Hispania and, as far as possible, make a critical analysis that helps clarify the number of fleets stationed in our coasts. It will be provided to this attention to existing epigraphic sources, relating them to classical and current sources, heading this way towards developing a thesis embedded in a broader framework to better understand the method of control and domination of romans in western mediterranean.
\end{abstract}

Key words: Hispania, army, navy, garrison, coasts. 


\section{INTRODUCCIÓN}

De un tiempo a esta parte se han venido exprimiendo las fuentes existentes sobre la conquista romana y la dominación progresiva y efectiva de Roma sobre el territorio peninsular, hasta el punto de que se ha logrado trazar un esquema básico dividido en etapas y fases fácilmente asimilables. No obstante parece que en esta labor se ha dejado al margen un aspecto muy importante y de valor vital en cuanto al análisis de la dominación romana. Hasta el momento sólo de forma complementaria y tangencial se ha hablado de la flota y su función en la Península Ibérica, un territorio predominantemente litoral y de peculiar y difícil relieve costero que hace forzoso la participación activa y continuada de unidades navales.

A través de los textos clásicos puede observarse que la flota romana jugaba un papel central y fundamental tanto en el comercio como en el control de los diferentes territorios que fueron quedando bajo su dominio; así, por ejemplo, es ampliamente reconocido el papel central que jugó la flota romana en la resolución de la primera guerra púnica donde tuvo que organizarse y reinventarse para poder hacer frente a la potencia marítima que suponía Cartago. Decisivo también fue el uso de la flota en las costas griegas entre el 231-228 a.C. cuando, bajo el gobierno de Teuta de Iliria, el auge de la piratería iliria llegó a amenazar la seguridad del Adriático. A nadie escapa así mismo el uso comedido pero decisivo que tuvo la flota en el desarrollo del segundo enfrentamiento entre romanos y cartagineses, o el innegable papel que esta jugó en la seguridad de las redes comerciales combatiendo antiguos núcleos de piratería como Baleares (Prieto, 1987-88). En la Península tampoco faltan ejemplos de relevante interés, algunos como la colaboración entre Sertorio y los piratas Cilicios es ya destacada por Plutarco o Salustio (Plutarco, Sert, 7, 3).

\section{LA FLOTA ROMANA EN LA PENINSULA IBERICA}

En las siguientes líneas se intentará arrojar algo de luz a cerca del papel de la flota romana en la Península Ibérica a través de la clarificación del número y, a ser posible, situación de la flota de guarnición romana a partir de las reformas de Augusto, que como sabemos contribuyeron por primera vez a una organización estable de la flota atendiendo a intereses militares y estratégicos desarrollados por él mismo y Agripa.

\subsection{Las élites hispanas en la flota romana.}

Cabe destacar en lo referente a este punto la escasa tradición en cuanto a su investigación, siendo muy poco lo escrito sobre el tema y siempre de manera marginal. No obstante, la presencia hispana en los cuadros del ejército romano fue muy elevada, en parte derivado de la temprana conquista de la península por parte de Roma, pero sobre todo de su pacificación definitiva con el emperador Augusto. Juan Manuel Abascal desde el estudio epigráfico dedica a este punto su atención en el artículo titulado La participación hispana en los ejércitos romanos (2009, pp. 289-300).

En lo que toca a los mandos de las legiones se nos dice que la participación hispana es baja en las primeras décadas del siglo I d.C, como consecuencia de la baja promoción de las élites locales al rango senatorial que sería el que otorga acceso a esta serie de puestos de alto rango. Esto no obstante cambiará al llegar al poder la dinastía Flavia (69-96), llevándose a cabo ya desde la llegada al poder de Vespasiano la concesión generalizada a toda Hispania del ius latii minor como nos indica Plinio el Viejo (Plinio, NH, 3, 30), permitiendo la creación de no pocos municipios en el último cuarto del siglo I d.C.

El primer hispano del que se tiene noticia comandando una legión es L. Cornelio Pusio, gaditano probablemente perteneciente a la familia de Cornelios gaditanos a la que pertenecieron los Balbos, 
que desarrollaron su carrera entre los gobiernos de Claudio (41-54) y Nerón (54-68). Durante el gobierno de Nerón sólo dos hispanos parecen estar al frente de legiones. Posteriormente el estallido de la guerra civil del 68-69 resultará un escenario perfecto para que determinadas familias senatoriales hispanas alcanzasen el poder y respaldo necesario para su promoción posterior a mandos legionarios. La tendencia de senadores hispanos con mando en tropa fue incrementándose, destacándose a $Q$. Pomponius Rufus, quien en tiempos del emperador Galba en el 68 adquirió el mando de la flota de Hispania y Galia y, veinte años después, comandó la legión V Macedónica en Moesia Inferior. Este incremento de las promociones hispanas alcanzó su punto álgido en tiempos de Trajano (98-117) y Adriano (117-138), decreciendo a partir de entonces la tendencia hasta el punto de que en tiempos posteriores la presencia de hispanos comandando legiones se reduce a dos casos, uno bajo Antonino Pio (138-161) y otro bajo Séptimo Severo (193-211).

De igual forma que los hispanos ocuparon cargos en las legiones también lo hicieron en unidades auxiliares hasta el punto de que tenemos constancia de 46 hispanos de rango ecuestre comandando 57 unidades auxiliares, aunque con seguridad solamente pueden ser identificadas 42 . Así mismo es de tener en cuenta que por regla general los comandantes hispanos siempre dirigen tropas en lugares diferentes del de su origen, aspecto este que se extrapola a todas las unidades el ejército.

Pero si hay algo que nos resulta especialmente interesante en estos aspectos es la comandancia de la flota romana. En este sector del ejército los hispanos ocuparon puestos de mando tanto en las escuadras principales del ejército como en aquellos contingentes que guarnecían de forma permanente las costas provinciales del Mediterráneo. Uno de los primeros individuos de los que se tiene constancia es M. Calpurnius Seneca Fabius Turpio Sentinatianus quien en tiempos de Adriano comando la flota de Ravenna y Misseno. También destacar al malacitano L. Valerius Proculus, prefecto de rango sexagenario de la flota Alexandrina y Potamophylacia en el norte de Egipto. Así mismo, si bien existe una gran escasez de datos referentes a las grandes flotas se tiene un amplio repertorio de ejemplos para las escuadras del Mediterráneo Occidental que guarnecían el litoral gálico, balear y las costa mediterránea peninsular. En este sentido vemos como el senador Q. Pomponius Rufus considerado como hijo de Sextus Pomponius (Plinio, HN, 25), recibió del emperador Galba en el año 68 la comandancia de flota encargada de vigilar las áreas mediterráneas de Hispania y sur de Galia. Destacamos también a los tarraconenses Ti. Claudius Paullinus y M. Clodius Martialis, que en fechas posteriores estuvieron comandando la flota encargada de guarnecer el litoral de la Hispania Citerior y que seguramente también garantizaría la seguridad de las Islas Baleares. En la vigilancia de la Hispania Citerior se conoce a otros individuos en su mayoría procedentes de Tarraco dado que de cinco de los que se tiene constancia, cuatro son de allí y el quinto de una familia de Baeculo. También debería contarse junto a estos a todos a los prefectos de esta guarnición costera y que aparecen reflejados en la siguiente lista.

En general se puede apreciar una gran cantidad de oficiales procedentes de Tarraco que no sólo parece ser sede de una hipotética flota romana del Mediterráneo Occidental sino que también sabemos que es la capital administrativa de la Hispania Citerior. En este sentido tenemos constancia tan solo de tres hispanos procedentes de la Baetica con mando en flota: de Ilipa, Malaca y Corduba respectivamente. Probablemente como analizamos más adelante, estas localizaciones deben tener su significado más certero en la mayor experiencia marítima de las zonas próximas al mar en detrimento de otras más interiores. En el caso Tarraconense también debe tenerse en cuenta la capitalidad que permitiría una mayor y rápida promoción de sus gentes, como así lo demostraría que muchos de los individuos aquí citados habían ostentado anteriormente mandos en unidades de infantería. 


\section{TESTIMONIOS EPIGRÁFICOS}

1- M. Calpurnius Fabius Turpio Sentinatianus

Origen: Ilipa o Hispalis

Unidad: Classis de Ravena, Classis de Misseno

Periodo: c. 130,134

Texto completo: M(arco) Calpurnio M(arci) filio / Gal(eria) Senecae Fabio / Turpioni Sentinatiano / praef(ecto) classis pr(aetoriae) Misenen/sis praef(ecto) classis praetoriae Ra/vennatis proc(uratori) provinciae / Lusitaniae et Vettoniae p(rimi) p(ilo) Leg(ionis) / I Adiutricis o(rdo) c(olonorum) c(oloniae) R(omulensis) / M(arcus) Calpurnius Seneca honore / usus impensam remisit

Bib: CIL II 1178 (p 841) = CILA II, 22 = ILS 2736 = HEp 14, 2005, 350 = Canto, A. Ma . "Los Viajes Del Caballero Inglés John Breval a España Y Portugal: Novedades Arqueológicas y Epigráficas de 1726." Revista Portuguesa de Arqueología 7/2 (2004), pp. 301, no 43, y 351, nota 176

2- L. Valerius Proculus

Origen: Malaca

Unidad: Classi Alexandria y Potamophylacia

Periodo: c. $118 / 129$

Texto completo: L(ucio) Valerio L(uci) f(ilio) Qui(rina) Proculo / praef(ecto) cohort(is) IIII Trachum(!) / Syricae trib(uno) milit(um) legion/is VII Claudiae P(iae) F(idelis) [- - -] / praef(ecto) classis Alexandrin(ae) / et Potamophylaciae proc(uratori) / Aug(usti) Alpium maritumar(um!) / delectatori Aug(usti) pro [- - - ] / provinc(iae) veteris Hispan(iae) / Baetic(ae) proc(uratori) provinc(iae) Cap/padociae proc(uratori) provinciae / Asiae proc(uratori) provinciarum trium / [Gallia]r(um) [proc(uratori) a rationib(us)] Aug(usti) / [prae]f(ecto) [ann]on(ae) [praef(ecto) Aegypti] r(es) p(ublica) / Malacit(anorum) patrono / d(onum) d(at)

Bib: CIL II 1970 = ILS 1341

3- Q. Pomponius Rufus

Origen: Hispania

Ámbito: Ora maritima Hispaniae citerioris et Galliae Narbonensis

Periodo: 68

Texto completo: Q(uintus) Pomponius Rufus co(n)s(ul) pont(ifex) sodal(is) Fla(vialis) cur(ator) oper(um) publicor(um) leg(atus) Aug(usti) / pro pr(aetore) provinc(iarum) [M] oesiae Dalmat(iae) Hisp(aniae) leg(atus) leg(ionis) V prae(fectus) orae marit(imae) Hispan(iae) citer(ioris) Gallia[e] / N[a]rbon(ensis) bello qu[od] Imp(erator) G[a]lba pro [rep(ublica)] gessit proco(n)s(ul) provinc(iae) Africae per L(ucium) Asinium Ru[fum] / [leg(atum) p]ro [pr(aetore) 3]

Bib: CIL VIII, 00013 
4- Ti.Claudius Paullinus

Origen: Tarraco

Ámbito: Insulae Baliarum et ora maritima

Periodo: 69/118

Texto completo: Ti(berio) Claudio / L(uci) f(ilio) Quir(ina) / Paullino / IIvir(o) q(uaestori) praef(ecto) / insularum / Baliaru[m et] / orae m[aritim(ae)]

Bib: CIL 02-14-02, 01014 = RIT 00167 = InsBaliares 00059 = AE 1956, 00022

5- M. Clodius Martialis

Origen: Tarraco

Ámbito: Insulae Baliarum (et ora maritima?)

Periodo: fines s.I - prin. s.II

Texto completo: $\mathrm{Cl}($ odi) $\mathrm{M}[\mathrm{a}] \mathrm{r}$ (tialis) // $\operatorname{Arg}()$

Bib: IRAT 00170

6- M. Porcius Narbonensis

Origen: Tarraco

Ámbito: Ora maritima (Hispaniae citerioris)

Periodo: c.98/118

Texto completo: M(arco) Porcio / M(arci) fil(io) Gal(eria) / Narbonensi / trib(uno) mil(itum) leg(ionis) XXII / praef(ecto) alae Thrac(um) / Herc(u)lan(ae) praef(ecto) / orae maritumae / flamini divorum Aug(ustorum) / provinciae Hisp(aniae) citer(ioris) / [p(rovincia) H(ispania) c(iterior)]

Bib: CIL II 4239 = RIT $301=$ AE 1971, 211

\section{7- L. Antonius Silo}

Origen: Tarraco

Ámbito: Ora maritima (Hispaniae citerioris), Cohors II tironum (Tarraco)

Periodo: fines s.I - pin. s.II

Texto completo: L(ucio) Antonio / T(iti) f(ilio) Gal(eria) Siloni / praef(ecto) fabr(um) praef(ecto) / c(o)hor(tis) IIII Tarrac(um) / praef(ecto) c(o)hor(tis) no/vae tironum praef(ecto) / orae maritumae / conventus Tar/raconensis

Bib: CIL II $4138=$ RIT $162=$ ILS 2715 


\section{8- L. Caecina Severus}

Origen: Tarraco

Ámbito: Ora maritima (Hispaniae citerioris)

Unidad: Cohors II tironum (Tarraco)

Periodo: fines s.I - pin. s.II

Texto completo: L(ucio) Caecinae / G(ai!) f(ilio) Gal(eria) Seve/ro IIvir(o) q(uaestori) / flamini praef(ecto) / fabr(um) praef(ecto) coh/ort(is) I et orae / marit(imae) / L(ucius) Valer(ius) Latinus / Barcinonen(sis)

Bib: CIL II 4264 = RIT 165 = ILS 2716

9- $[\ldots]$ rius Fuscus

Origen: Tarraco

Ámbito: Ora marítima (Hispaniae citerioris)

Periodo: fines s.I - pin. s.II

Texto completo: [---]rio / Q(uinti) [fil(io) Gal(eria?)] Fus[c]o(?) / IIvir(o) flam(ini) divi / Claudi praef(ecto) orae / marit(imae) / flamini divorum et / Augustor(um) p(rovinciae) H(ispaniae) c(iterioris) provinc(ia) / Hispania citer[ior] / [or]do Tarraconens(ium) / honores decrevit

Bib: CIL II 04217 = RIT 316 = HEp 9, 1999, 535 = AE 1999, 966 = AE 2000, 115 = Fischwick, D. 1999. “A Municipal Decree at Tarraco." ZPE 126: 291-95.

10- Q. Licinius Silvanus Granianus

Origen: Baetulo?

Ámbito: Ora maritima Leetana (sic)

Texto completo: Imp(eratore) Nerva Caesar(e) Traiano / Aug(usto) Germ(anico) II / C(aio) Pomponio Pio co(n)s(ulibus) / VI Idus Iunias / Baetulonenses ex Hispania citerio/re hospitium fecerunt / cum Q(uinto) Licinio Silvano Graniano / eumque liberos posterosque / eius sibi liberis posterisque / suis patronum cooptaverunt / Q(uintus) Licinius Silvanus Grania/nus Baetulonenses ex His/pania citeriore ipsos libe/ros posterosque eorum in / fidem clientelamque suam / liberorum posterorum/que suorum recepit / egit legatus / Q(uintus) Caecilius Tertullus

Periodo: c.69/79

Bib: IRC I, 139; $A E$ 1936, 6

11- L.Cornelius Celsus

Origen: Tarraco

Unidad: Cohortes I et II novae toronum (Tarraco) 
Periodo: fines s.I - pin. s.II

Texto completo: L(ucio) Cornelio / C(ai) f(ilio) Gal(eria) Celso / IIvir(o) praefecto / orae maritmae / cohortis I et II / Pompeia Donace / uxor

Bib: CIL 02, 04266 (p LXXVIII, 973) = CIL 05, p 771 = CIL 02-14-02, 01016 = D 02717 = RIT 00169

12- P. Licinius Laevinus

Origen: Tarraco

Unidad: Cohors nova tironum

Periodo: fines s.I - prin. s.II

Texto completo: P(ublio) Licinio / L(uci) f(ilio) Gal(eria) / Laevino / aed(ili) q(uaestori) flamini Ro/mae et Aug(ustorum) IIvir(o) / praef(ecto) c(o)hor(tis) novae ti/ronum orae marit $<\mathrm{i}=\mathrm{U}>$ mae / Iulia Q(uinti) f(ilia) / Ingenua mater

Bib: CIL 02, 04224 (p LXXVIII, 973) = CIL 02-14-02, 01019 = RIT 00171

13- [L.?] Iulius Gallus Mummianus

Origen: Corduba

Unidad: Cohors maritima (Tarraco)

Periodo: c.98/117

Texto completo: Iulio M(arci) f(ilio) Q(uinti) nep(oti) / Gal(eria) Gallo / Mummiano trib(uno) / militum coh(ortis) maritimae / IIviro c(olonorum) c(oloniae) P(atriciae) flamini / divor(um) Aug(ustorum) provinc(iae) / Baeticae / huic ordo c(olonorum) c(oloniae) P(atriciae) statuam / equestrem decrevit / Aelia Flaviana uxor / honore usa impensam / remisit

Bib: CIL 02-07, 00282 = CIL 02, 02224 = D 06905

14- Lucius Valerius Proculus

Origen: Malaca

Unidad: classis Alexandrina et Potamophylacia

Texto completo: L(ucio) Valerio L(uci) f(ilio) Qui(rina) Proculo / praef(ecto) cohort(is) IIII Trachum(!) / Syricae trib(uno) milit(um) legion/is VII Claudiae P(iae) F(idelis) [- - -] / praef(ecto) classis Alexandrin(ae) / et Potamophylaciae proc(uratori) / Aug(usti) Alpium maritumar(um!) / delectatori Aug(usti) pro [- - - / provinc(iae) veteris Hispan(iae) / Baetic(ae) proc(uratori) provinc(iae) Cap/padociae proc(uratori) provinciae / Asiae proc(uratori) provinciarum trium / [Gallia]r(um) [proc(uratori) a rationib(us)] Aug(usti) / [prae]f(ecto) [ann]on(ae) [praef(ecto) Aegypti] r(es) p(ublica) / Malacit(anorum) patrono / d(onum) d(at)

Periodo: siglo I - prin siglo II d.C.

Bib: CIL II 1970 = ILS 1341 
Como podemos observar en los testimonios expuestos, los primeros nombres que nos aparecen quedan asociados al sur peninsular. Este es un aspecto que puede resultar interesante si lo ponemos en relación con la más que posible tradición marinera que pudo haberse desarrollado en la zona de influencia fenicia (Frankenstein, 1997; Hawkes, 1969, pp. 185 y ss; Plinio, NH, 2). En efecto, la colonización fenicia no tenía por objetivo ser una simple expansión territorial sino crear una esfera comercial en occidente que en cierto modo permitiese la reproducción del sistema económico regional del que las ciudades fenicias formaban parte. En una primera fase en torno al siglo VIII a.C. los comerciantes fenicios utilizarían en la península ibérica los circuitos comerciales preexistentes de origen atlántico para ganar el acceso a los recursos metalíferos. En una segunda fase de la colonización los intercambios y la producción se intensificarían ya bajo el control fenicio, pasando entonces sus centros coloniales de simples centros de intercambio a ser centros industriales orientados al mercado indígena. La población indígena controlaría los recursos de mineral en tanto su comercio quedaría monopolizado por los fenicios, quienes a su vez ofrecerían a los indígenas la tecnología y conocimientos necesarios para la producción. Por tanto, los establecimientos fenicios en el litoral andaluz serian centros de comercio, producción y aculturación. En tanto algunos asentamientos estarían más orientados a una producción especializada, habrían otros que se centrarían en una importante producción de alimentos al no ser suficientes con aquellos ofrecidos por los territorios indígenas más cercanos. Estas fundaciones estarían habitadas por colonos fenicios e importantes elementos indígenas plenamente incorporados a las actividades productivas y comerciales (López, 1992, pp. 11-79) entre las que se incluiría muy posiblemente la pesca.

En este sentido y a fin de que resulte más ilustrativo lo mencionado no puede dejar de citarse los resultados extraídos en 1981 del análisis ictológico sobre los restos de la Calle del Puerto 6 (Huelva) donde los restos corresponden a un mismo nivel de ocupación continuado entre el VIII y VI a.C. Aquí, se ha podido constatar la existencia de 14 tipos diferentes de peces destacando la gran variedad de los mismos. Si bien es cierto que con estos datos no se pueden hacer grandes afirmaciones cuantitativas fiables si puede constatarse una gran riqueza en cuanto a producto pesquero se refiere. Así mismo no sólo se tiene constancia de especies costeras sino que se han recuperado un número importante de restos pertenecientes a especies neríticas o pelágicas, es también de destacar el enorme tamaño de los individuos capturados según parece inferirse de los restos recuperados, aunque no obstante es probable que esto ultima pueda deberse a la recuperación parcial de los restos habiéndose perdido los de menor tamaño (Roselló, Morales, 1990, pp. 291-298).

En relación a esto último debe sacarse a colación la calidad de la tecnología pesquera que como ya resultará evidente debe de ser altamente sofisticada incluyendo arpones, anzuelos y redes variadas, no descartando tampoco la posible existencia de trasmallados, liñas o palangres. De cualquier modo esto viene a indicarnos la importante riqueza del litoral andaluz en fauna íctia si la comparamos con otros estudios faunísticos similares en otras zonas de la península.

De lo que no cabe ninguna duda es que la riqueza litoral de esta zona debió de ser percibida ya desde bien antiguo por sus propios habitantes y poblaciones litorales quienes sin lugar a dudas tuvieron que saber explotarlas de un modo adecuado y rentable. Y es aquí, donde retomando la idea inicial debemos sacar a relucir la más que probable tradición marinera que se extendería por toda la costa del sur peninsular, tradición que todavía gozaría de cierto prestigio a la llegada de los romanos y que motivaría en esta zona los primeros nombramientos a comandante de flota.

Resulta aclaratorio mencionar aquí el pasaje que recoge Plinio (Plinio, NH, 2, 169), una historia de naves hispanas que por determinadas razones naufragan en el Golfo Arábigo; en Alejandría reconocieron sus restos como parte de alguna expedición gaditana que habiéndose alejado demasiado de Lixus acabaron por naufragar. De este naufragio dedujo Eudoxo que circunnavegar África no 
resultaría imposible, y es a partir de este hallazgo que intentará tal travesía partiendo de Gadir haciéndose acompañar de importantes y buenos marinos de la ciudad fenicia. La travesía se realizaría con un gran barco y con dos más pequeños; de vuelta fletó en Hispania, en el sur, un Stronngylos, barco comercial o de transporte, y un Pentekonteros, uno para la navegación en alta mar y otro para la de cabotaje o costera. Plinio cuenta que el analista del tiempo de los Gracos, Celio Antipater conoció un comerciante que había hecho la circunnavegación de África partiendo de Hispania y llegando a la costa Este de África (Plinio, NH, 2, p. 169, en García y Bellido, 1953, pp. 234 y ss.). En estos viajes, debieron utilizar los gaditanos técnicos, buques y la gran tradición marinera de los tartesios, como lo probaría el hecho de que en el año 216 a.C utilizasen los cartagineses la flota tartesica en la lucha naval con los romanos (Hawkes, 1969, pp. 185 y ss.), lo que se deduce del hecho de que los prefectos de las naves, tras el abandono de la flota en el Ebro, se resguardasen en la Turdetania donde sublevaron a algunas poblaciones contra Cartago (Livio, 23, p. 26).

Así mismo, debemos tener en cuenta que los viajes a la costa Africana desde Hispania eran muy comunes, según podría extraerse del intento de Sertorio por llegar a las Islas Afortunadas (Plinio, NH, 6, p. 202). Nos cuenta Plinio (NH, 2, pp. 167-168) que se partía de Gades para recorrer el Atlántico en ambas direcciones. Gades mantenía contacto comercial con el norte de Marruecos como lo atestiguan 100 monedas fenicias y otras 50 procedentes de Hispania. Como apunta Euzennat (1965, pp. 273 y ss.) Marruecos debió ser una especia de extensión de la Bética, más concretamente de Cádiz.

Posteriormente, una segunda fundación romana con importante comercio y que aprovecha la mencionada tradición marinera fue Hispalis (Blanco, 1972, pp. 3 y ss.), que a finales de la republica fue suplantada en importancia por la fundación cesariana de Itálica (Garcia y Bellido, 1960, pp. 508 y ss.). Tras estas dos ciudades destacan Ilipa sobre el Betis; Astigi (Garcia y Bellido, 1969, pp. 481 y ss.); más lejos Carmona, cuyas excavaciones revelan la profunda romanización del lugar ya en época julioclaudia; Obulco y Munda, metrópoli de este territorio; Ategua (Teba la Vieja); Urso (Osuna) (Thuvenot, 1942, pp. 392 y ss.), Tucci (Martos) (Cabezón, 1964, 106 y ss.) y Ulia (Montemayor) (Estrabón, 3, p. 141). En los esteros la ciudad más famosa era Asta (García y Bellido, 1969, pp. 460 y ss.) que se encontraba a poco más de 18 kilómetros del arsenal de Cádiz, donde acostumbraban a reunirse los gaditanos. Otra ciudad de gran importancia comercial fue Malaca, mercado para los nómadas del norte de África (Estrabón, 3, p. 141). La ciudad debió ser algún tipo de centro metalúrgico o de exportación metalífera de la serranía de Córdoba, como se deduce del hecho de que en sus monedas se representan los elementos de forja de un Baal metalúrgico. Sigue en importancia Sexi, lugar en el que se ha encontrado una de las necrópolis fenicias más antiguas de occidente, datada en torno al 700 a.C (Blázquez, 1968, pp. 216 y ss.). Abdera también era fundación fenicia (Estrabón, 3, p. 157).

En general y según los datos que nos cuenta Estrabón (3, pp. 142-3) puede afirmarse que aquellos productos sobrantes en la Bética se comercializaban mediante numerosos barcos de comercio. Se deduce que esta importancia alcanzaría cifras extraordinariamente elevadas (Estrabón, 3, p. 144). Los mayores navíos de carga que llegaban a Puteoli y a Ostia era casi igual al que procedía de África, Puteoli fue el mayor puerto de Italia y la clave del comercio con Oriente, posteriormente vio suplantada su importancia por Ostia ${ }^{1}$ después de la construcción del puerto artificial en esta ciudad.

Algunas ciudades vivian exclusivamente del comercio y empresas marineras como Cádiz, lo que explica que en un censo efectuado, el número de caballeros fuese realmente elevado, el segundo tras Padua (Blázquez, 1978, 64). Esto puede ayudarnos a comprender que en los primeros momentos gran parte de la oficialidad hispana con comandancia en flota fuese reclutado entre las ciudades del sur de la península.

1 Fue iniciado por Claudio, ampliado por Nerón y reconstruido por Trajano. 


\subsection{Navegación y estacionamiento en la Península Ibérica.}

Hace unos años, Eduardo Gimeno llevó a cabo un estudio centrado en el papel desempeñado por la armada romana durante la Segunda Guerra Púnica en el contexto de la Península Ibérica (Gimeno, 2011). Este estudio resulta interesante en el sentido en que nos permite apreciar las principales formas de estacionamiento de las flotas romanas en nuestro marco de estudio en un periodo en el que la península carecía casi por completo de puertos adecuados y estables (Gnome 1933, p. 19).

En este sentido y respecto a los modos de estacionamiento o atraque y dada la escasa documentación arqueológica y documental que se posee, solo se puede aventurar que en los inicios de la presencia romana en la Península Ibérica, durante la Segunda Guerra Púnica, no debieron existir en las costas peninsulares grandes ciudades portuarias, a excepción de Qart Hadasht (Berrocal, 1998). Por lo tanto Roma debió de conformarse con las deficientes instalaciones portuarias existentes, con pequeños fondeaderos naturales, calas etc., aunque no se puede descartar la modificación temporal de determinados lugares para la mejora del atraque.

Descontando el puerto de Qart Hadasht las principales formas para estacionar de los romanos serían el fondeado y el varado.

Apoyándose en la lógica, la manera más común de estacionamiento seria el fondeado en pequeñas calas resguardadas de las corrientes y en desembocaduras de ríos que facilitan el acceso al agua dulce. En nuestro caso destacamos el puerto natural de Emporion que según las últimas prospecciones geofísicas funcionaria como fondeadero en el contexto de la Segunda Guerra Púnica; y el caso del fondeado de la flota en los momentos previos a la batalla de Ebro donde Polibio cuenta como la flota fondeo a 10 estadios de la desembocadura del río (Gimeno, 2011).

La otra forma también bastante común debió ser el varado. En previsión de temporales o de la parada invernal del ejército se procedería a varar las naves en la playa para mayor seguridad. Es de suponer que la flota romana invernaría cada año en Tarraco desde el 217 a.C., aunque solo se encuentra evidencia certera de ello para los inviernos del 217 -216 a.C. y 210-209 a.C. Livio nos describe el momento en que fueron varadas las naves y el momento en que fueron botadas en primavera con motivo de la expedición contra Qart Hadasht (Livio, 26, p. 17).

Así mismo se tiene registro de una mención a la varada de una flota por parte del bando cartaginés en el 216 a.C., Livio (23, 28, pp. 2-3) nos cuenta que Himilcón:

...hizo la travesía con las tropas de mar y tierra y atrinchero el campamento, y saco las naves a tierra y las rodeo de una empalizada...

Aunque este episodio haga referencia al ejército cartaginés, se debe tener en cuenta que puede constituir una de las evidencias más importantes del método que podría utilizar la flota de guerra en marcha para estacionarse, sobre todo si se encontraba en territorio hostil.

Estos castra navalia, nos aparecen en las fuentes si se sigue la crónica de la Segunda Guerra Púnica en Livio y Polibio. Se encuentran así referencias a diversos emplazamientos en que se produjo el estacionamiento de la flota romana. Nova Classis, Saguntum ${ }^{2}$, Sucro y Qart Hadasht, todos susceptibles de haber contado con castra navalia todos ellos formando una línea de norte a su coincidente con el avance romano.

2 En el caso de Saguntum, arqueológicamente se conoce la existencia de una laguna apta para fondear naves. Por si no fuese suficiente, las descripciones del episodio del rescate de rehenes en el 217 a.C. dicen que los Escipiones construyeron un campamento en una posición cercana a la costa a fin de controlar la flota y poder retirarse en caso de emergencia (Polibio 3, 97, pp. 6-8). 
Por tanto, la crónica que estos autores realizan nos resulta de suma utilidad para entender y comprender los medios utilizados por los romanos para navegar y atracar en nuestras aguas y de esta forma poder esbozar la evolución existente en las mismas hasta llegar a la dinastía Julio-Claudia en la que la Península se encuentra plenamente integrada en la administración territorial romana.

\section{INTERVENCIONES NAVALES EN LA PENÍNSULA IBÉRICA.}

Actualmente puede decirse que no existen pruebas suficientes como para poder afirmar la existencia continuada de flota en los puertos hispanos durante el periodo de final de la república y todo el periodo imperial. No obstante, como aventura Kienast (1966, p. 97) es asumible la existencia de una base naval en Gades. A finales de la republica constatamos la existencia por ejemplo de las naves de Varrón para combatir a César (César, Bellum Civile, 2, p. 18). Así mismo no debe pasarse por alto la considerable tradición naval de esta zona, ya comentada al principio y que supuso una importante actividad en esta zona aun durante periodo imperial (Gagé, 1951, pp. 189-216). No obstante pasado el episodio de César no parece haber nada más, ni rastro de actividades de flota en estas agua. Plinio nos habla pese a todo de un viaje muy breve entre Gades y Ostia de siete días de duración (Plinio, 19, p. 3):

Sed in qua non occuret uitae parte, quodue miraculum maius, herbam (Le. linum) esse quae admoueat Aegyptum Italiae in tantum ut Galerius a freto Siciliae Alexandriam septimo die peruenerit, Balbillus sexto, ambo praefecti, aestate uero post XV annos Valerius Marianus ex praetoriis senatoribus a Puteolis nono die lenissumo flatu? Herbam esse quae Gades ab Herculis columnis septimo die Ostiam adferat et citeriorem Hispaniam quarto, prouinciam Narbonensem tertio, Africam altero, quod etiam mollissumo flatu contigit C. Flauto legato Vibii Crispi procos?

Kienast cree que se trata de navegación a remo, y que por lo tanto Gades podría albergar una base de la flota del Miseno mostrándose contrario a la utilización de velas como las que dice Plinio a base de lino. No obstante, si se niega la existencia de una base permanente en Gades, no puede excluirse la más que probable posibilidad de patrullas recurrentes a lo largo de la costa de Hispania. En este sentido, se cuenta con el testimonio de un marino de la flota de Ravena muerto en Dertosa, en la Tarraconense ${ }^{3}$. En cuanto a la flota de Mauritania, de la que habitualmente se tiende a pensar que realizaría labores de patrullaje por las costas hispanas, cabe decir que apenas se tienen testimonios firmes de que realmente cumpliese dicha función, aunque su presencia durante la guerra contra los mauros en la Bética es bastante probable (Thouvenot, 1939, pp. 20-28). En tiempos ordinarios la defensa de ciertas costas se efectuaría eminentemente desde tierra.

\subsection{El caso de la costa Atlántica}

A partir de las escasa fuentes clásicas existentes sobre la conquista del norte peninsular se puede llegar a esbozar un esquema básico en lo que refiere al avance y movimiento de las tropas terrestres por el territorio. No obstante, tan solo secundariamente se ha hablado sobre la intervención de la flota

3 CIL II 4063:D(tis) M(anibus),/L(ucius) Numisius Li/beralis,mil(es) cl(assis) pr(aetoriae) Rauenn(atium),/(triere) Mart(e), stip(endiis) (tredecim),/nat(ione) Cursican(us),/M(arcus) Didius Pol/(l)io heres et com/manup(ularìs), et Gellia/ Excitata. 
en un territorio que por su localización y litoralidad hace necesaria la participación de elementos de flota, cuyo análisis va a resultar útil y necesario para la comprensión del funcionamiento de la flota en la Península Ibérica.

En este marco geográfico podemos diferenciar a grandes rasgos cuatro momentos que a su vez manifiestan muy bien la evolución de la flota romana según los parámetros anteriormente tratados. El primero de estos momentos correspondería con la expedición militar de Bruto entre el 138-137 a.C., el segundo correspondería con la expedición exploratoria de Publio Craso en busca de las Casitérides entre el 96 y 94 a.C., el tercero correspondería con la incursión de César entre el 61 y 60 a.C. y el ultimo, la definitiva intervención y conquista por parte de Augusto en el 25 a.C. del Norte peninsular.

En cuanto a la intervención de Junio Bruto debemos tener en cuenta primeramente las fechas. Unas fechas en las que Roma no solo no contaba todavía con una flota mínimamente organizada y estable, sino que se encontraba en un periodo decadente en el que su necesidad de flota quedaba apoyada en Oriente por las embarcaciones prestadas por su aliados y socios comerciales. Pese a esto no se puede descartar la posible intervención de embarcaciones comerciales pertenecientes a ciudades ya subyugadas situadas en la costa Norte para labores de transporte y logística, aunque esto no deja tampoco de ser simple especulación sobre la lógica de lo posible. Lo cierto es que en el Mediterráneo se aprecia una clara dicotomía entre un Occidente con una flota inexistente y Oriente donde el apoyo en aliados atenúa la manifiesta carencia.

No obstante Bruto pudo haber utilizado algunas naves procedentes de Gades o Hispalis si tenemos en cuenta la profunda tradición marinera comentada con anterioridad, o Carteia si se tiene en cuenta que utilizó el cauce del Tajo para enfrentar a los Lusitanos (Apiano 6, pp. 73-75). Casimiro Torres (1982) va más allá y aventura la existencia de una posible flota de apoyo cercana al litoral y que podría estar en conexión con el ejército terrestre, pero la ausencia de fuentes al respecto hacen que no pueda pasar de una simple hipótesis, más aun si tenemos en consideración que autores como Rodríguez Colmenero (1995, pp. 91-100) defienden que el paso del ejército de Bruto para combatir a los Lusitanos debió de producirse por el interior una vez sobrepasado el Duero, si se atiende a su condición de vencedor de los Galaicos, ya que como dice Plinio entre este pueblo y la costa se interpone el territorio de los Brácaros (Plinio, 4, 34, p. 112).

El que Junio Bruto decidiese, pasado el Duero, y una vez sometida ya la ciudad de Talabriga, regresar a Roma pasando por la Celtiberia para socorrer a Lépido (Apiano, 14, pp. 80-82) ahonda en la idea de que no se contaba con flota o de que esta debía ser únicamente de avituallamiento. De modo que, a falta de mejores datos, puede por ahora decirse que Bruto utilizó esencialmente en su campaña tropas de tierra con una ayuda marítima o fluvial muy circunstancial y secundaria.

Respecto al segundo momento clave, la expedición del procónsul Publio Craso, se produjo entre los años 96 y 94 a.C, se trataba de una expedición de exploración en la que se pretendía encontrar las islas Casiterides (Estrabón, 3, pp. 3,6, 7). Básicamente se trataba de explorar las antiguas y en ocasiones míticas rutas de los metales que los tartesios y cartagineses hubieron monopolizado en su día y que posteriormente habría caído en manos de la ciudad de Gades.

La incursión de Julio César entre el 61 y 60 a.C, cuatro años más tarde que Craso, se lleva a cabo hasta Brigantium. César se apoyaría en las naves gaditanas que realizarían este recorrido de forma medianamente frecuente. César, persigue a los habitantes del Monte Herminio que huyen a una isla próxima al litoral lusitano, que algunos sitúan en Peniche (Colmenero, 1995, p. 93) y otros en las islas Cíes (Torres, 1982). De cualquier modo el plan de César parece responder a un plan bien meditado de depredación metalífera más que a una simple persecución de un pueblo hostil (Colmenero, 1995, p. 93). En cuanto al radio de penetración, tierra adentro, que Julio César se planteó, poco o nada 
es lo que se sabe, aunque según Rodríguez Colmenero no debió de rebasar mucho las alineaciones montañosas de un litoral que recorría en casi todos los entrantes, internándose incluso por el curso bajo de los ríos que en él desembocaban. En cualquier caso el punto de atención parece ser más bien la localización de Brigantium cuya localización todavía ofrece problemas, aunque probablemente se sitúe en algún punto próximo de A Coruña histórica. También parece, que al viaje de César, deben atribuírsele finalidades científicas del tipo geográfico/cartográfico complementarias a las aportaciones de Posidonio rememoradas por Estrabón, como parece demostrar la fina estrategia y dominio cartográfico de los generales romanos durante las guerras cántabras.

Finalmente llegamos al periodo augusteo. El propio Augusto decide intervenir personalmente en el definitivo sometimiento del Finisterre Hispánico. En el año 27 a.C, una vez que su figura ha sido reforzada a través de diversas reformas de dudosa legitimidad, asigna a la figura del príncipe la provincia de la Citerior dentro de la cual se incluiría la zona de Cantabria. En este punto resulta de interés prestar atención al puerto fortificado de Forum Iulii (Frejus), puesto que, Reddé (1986) considera que en las costas de Hispania no existieron puertos militares pese a que Gades suministrase barcos a Varrón contra César, dado que estos serían seguramente de carácter comercial (César, Bellum Civile, 2, p. 18). Pese a esto no se puede descartar que, en ocasiones puntuales, se empleasen destacamentos militares como para Dertosa testimonia una lápida funeraria de un marino de la flota de Ravena (Colmenero, 1995, p. 96), pero en ningún caso de forma continuada o permanente, ni tan siquiera durante el Bajo Imperio, momento en el que las tropas acantonadas en Hispania serían casi exclusivamente terrestres (Balil, 1960, pp. 179 y ss; 1970, pp. 606 y ss.).

En este sentido, los episodios mencionados por Floro (pp. 2, 33, 48) y Orosio (pp. 6, 21, 34) sobre la intervención de la flota de Aquitania en las guerras cántabras podría estar respondiendo a una planificación más amplia y cavilada de lo que parece aparentar. En cualquier caso Augusto, en el 27 a.C pudo haber realizado el viaje a Tarraco por mar (Colmenero, 1995, p. 97). Al tratarse de una expedición oficial sería coherente que se hubiese hecho acompañar de una flota militar, como también veremos qué sucederá en el viaje de Agripa en el 14 a.C. a las costas orientales (Josefo, BI, 16, p. 21), o Germánico por el litoral griego (Tácito, Annales, 2, p. 53) o Calígula en su marcha a Egipto (Filón, Legatio ad Gaium, pp. 250-252).

Lo interesante de la estrategia de Augusto radica en la utilización de una maniobra de tenaza, en la que se verían implicadas fuerzas navales de norte a sur y unidades terrestres que atacasen de sur a norte. Por tanto, ya no se trata en este caso de una operación sencilla de avituallamiento sino de un embarque de tropas en Aquitania que con la flota avanzan hacia el litoral cantábrico, donde previsiblemente realizarían desembarcos rápido y contundentes que junto a las fuerzas llegadas del sur lograrían desorganizar y a avasallar al enemigo (Colmenero 1995, p. 97). Seguramente, como ya mencionaba Fieliger (Classis, en RE, III col. 2636), la base de operaciones navales se situaría en Forum Iulii, dado que sería la más occidental de las hasta ahora conocidas. Esta estrategia seria también utilizada con posterioridad en la conquista de Germania (Suetonio, Claudius, 1, p. 2) y Britania (Tácito, Agricola, 29, p. 2; 25, pp. 1-2) como nos dan a conocer los autores clásicos.

En definitiva es realmente poco lo que se conoce a cerca de episodios de intervención de flota en el litoral cantábrico y todos ellos se circunscriben a las guerras cántabras, en la que los datos sobre la flota son exiguos y tan solo permiten extraer conjeturas más o menos certeras.

\subsection{El caso de la costa Mediterránea.}

En la costa mediterránea destacamos principalmente el litoral de la Tarraconensis, donde la participación de praefectii orae maritimae se encaja en una concepción de la defensa más estática y terrestre que móvil y marítima (Barbieri, 194, pp. 268-280). La única operación naval de cierta 
envergadura de la que parece tenerse noticia es la ocurrida entre 197 y 199 d.C. En estas fechas, Tiberio Claudio Candido, uno de los generales más conocidos de Séptimo Severo, se encontraba en Hispania Citerior, dux terra marique adversus rebelles ${ }^{4}$. De cualquier forma no se sabe exactamente quienes eran esos rebeldes, así como tampoco se sabe nada al respecto de las fuerzas con las que entonces contaría Candido (Alfòldy, 1969, pp. 43-45). Pese a esto, la ausencia de toda referencia dentro de la historia imperial, a una flota autónoma en Hispania permite pensar que el legado de Séptimo Severo tuviese a su disposición alguna flotilla local que desconocemos o bien que pudiese estar utilizando algún destacamento de las flotas pretorianas, aunque debe tenerse en cuenta que en estos momentos el grueso de estas flotas se encontraba en Oriente. En el resto del periodo imperial, la situación parece semejante, la defensa del territorio de Hispania, a excepción quizá del norte, parece realizarse eminentemente desde tierra (Balil, 1960, pp. 179 y ss.). En este punto tenemos como dato de interés la expedición realizada en el 460 contra los vándalos, expedición que bordeó las costas de Hispania y que finalmente fue destruida por los bárbaros en algún punto entre Alicante y Cartagena, y que además se trataba de una flota llegada de las costas de Italia, lo que nos indica ausencia de flota estable en nuestras costas, como mínimo en lo referente a este momento.

\section{CONCLUSIÓN.}

Basándonos en todos los datos recopilados, puede decirse que no existen pruebas suficientes como para poder afirmar la existencia continuada de flota en los puertos hispanos durante el periodo final de la república, situándose pues la duda en la horquilla comprendida entre el siglo I y II d.C. No obstante, como aventura Kienast (1966, p. 97) es asumible la existencia de una base naval en Gades. A finales de la República constatamos la existencia por ejemplo de las naves de Varrón para combatir a César (Bellum Civile, 2, 18). Así mismo no debe pasarse por alto la considerable tradición naval de esta zona, ya comentada al principio y que supuso una importante actividad en esta zona aun durante el periodo imperial (Gagé, 1951, pp. 189-216). No obstante pasado el episodio de César no parece haber nada más, ni rastro de actividades de flota en estas agua. Plinio nos habla pese a todo de un viaje muy breve entre Gades y Ostia de siete días de duración (Plinio, 19, p. 3):

Sed in qua non occuret uitae parte, quodue miraculum maius,

herbam (Le. linum) esse quae admoueat Aegyptum Italiae in tantum ut Galerius a freto Siciliae Alexandriam septimo die peruenerit, Balbillus sexto, ambo praefecti, aestate uero post XV annos Valerius Marianus ex praetoriis senatoribus a Puteolis nono die lenissumo flatu? Herbam esse quae Gades ab Herculis columnis septimo die

Ostiam adferat et citeriorem Hispaniam quarto, prouinciam Narbonensem tertio, Africam altero, quod etiam mollissumo flatu contigit C. Flauto legato Vibii Crispi procos?

Kienast cree que se trata de navegación a remo, y que por lo tanto Gades podría albergar una base de la flota del Miseno mostrándose contrario a la utilización de velas como las que dice Plinio a base de lino. No obstante si se niega la existencia de una base permanente en Gades no puede excluirse la más que probable posibilidad de patrullas recurrentes a lo largo de la costa de Hispania. En este sentido se

4 CIL II, 4144; Fitz 1966, 831-846: Tib(erio) Cl(audio) Candido, co(n)suli,/quindecemvir(o) s(acris) f(aciendis), leg(ato) Augfustorum) (duorum)/pr(o) pr(aetore) prouinc(iae) H(ispaniae) c(iterioris),/et in ea duci terra marique/ aduersus rebelles h(omines) h(ostes) p(ublicos) p(opuli) Rfomani)/... 
cuenta con el testimonio de un marino de la flota de Ravena muerto en Dertosa, en la Tarraconense ${ }^{5}$. En cuanto a la flota de Mauritania, de la que habitualmente se tiende a pensar que realizaría labores de patrullaje por las costas hispanas, cabe decir que apenas se tienen testimonios firmes de que realmente cumpliese dicha función, aunque su presencia durante la guerra contra los mauros en la Bética es bastante probable (Thuvenot, 1939, pp. 20-28). En tiempos ordinarios la defensa de ciertas costas se efectuaría eminentemente desde tierra.

En lo referente al periodo imperial debería centrarse la atención en Tarraco. Tarraco no sólo es la capital administrativa de la Hispania Citerior sino que las primeras noticias de atraque de flota se remontan ya al 217 a.C., momento en el que según Livio la flota romana invernó en el 217 - 216 a.C., y en el 210 - 209 a.C., con motivo de la expedición contra Qart Hadasht. Además, disponemos de numerosas evidencias de la existencia de escuadras marítimas destinadas a proteger el Mediterráneo hispano, gálico y balear. En este sentido, y trayendo a colación lo visto con anterioridad vemos como Q. Pomponius Rufus, recibió del emperador Galba en el año 68 la comandancia de una flota encargada de vigilar las costas mediterráneas de Hispania y sur de Galia. Aparte, resuenan con mayor fuerza si cabe los nombres de los tarraconenses Ti. Claudius Paullinus y M. Clodius Martialis, que en fechas posteriores estuvieron comandando la flota encargada de custodiar y proteger el litoral de Hispania Citerior y probablemente tuviese como tarea también la vigilancia de las Baleares. Así mismo, en la protección de la costa occidental de Hispania debe tenerse en cuenta a otros individuos mencionados en el listado epigráfico en el que se aprecia como, al menos, cuatro son procedentes de Tarraco y un quinto de una familia de Baeculo. No podemos olvidar tampoco a todos los praefectos de la misma guarnición y que también aparecen reflejados en los textos epigráficos. Al hablar de Tarraco, tampoco podemos olvidar la gran influencia ejercida derivada de ocupar la posición de capitalidad, dado que numerosas gentes se ven beneficiadas de una rápida promoción. Este aspecto vendría avalado por la gran cantidad de oficiales citados en este mismo trabajo y que con anterioridad a poseer un cargo en flota habían ostentado un mando en alguna unidad terrestre.

\section{BIBLIOGRAFÍA}

Abascal, J.M. (2009), La participación hispana en los ejércitos romanos, Historia militar de España I, Prehistoria y Antigüedad, 289-300.

Alföldy, G. (1975). Die Römischen Inschriften von Tarraco, Berlin.

Balil, A. (1960), La defensa de Hispania en el bajo imperio, Zephyrus, XI, 179 y ss.

Barbieri, G. (1941), Praefectus orae maritimae, Rivista di Filologia, 19, 268-280.

Berrocal, M.C. (1998), Instalaciones Portuarias en Carthago Nova: La evidencia arqueológica, en III Jornadas de arqueología subacuática: puertos antiguos y comercio marítimo: Facultat de Geografía i Història de Valencia 13, 14, y 15 de noviembre de 1997, 1998, pp. 101-114.

Blanco y Freijeiro. (1972). Arte antiguo del Asia anterior, Sevilla.

Blázquez, J.Mà. (1968). Tartessos y los orígenes de la colonización fenicia de Occidente, Salamanca.

Blázquez, J.Mà. (1978). Historia económica de la Hispania romana, Madrid.

Cabezón, A. (1987). Epigrafía tuccitana, AEspA, 106 y ss.

5 CIL II 4063:D(tis) M(anibus),/L(ucius) Numisius Li/beralis,mil(es) cl(assis) pr(aetoriae) Rauenn(atium),/(triere) Mart(e),stip(endiis) (tredecim),/nat(ione) Cursican(us),/M(arcus) Didius Pol/(1)io heres et com/manup(ularìs), et Gellia/ Excitata. 
Colmenero, A.R. (1995), La intervención de la flota romana en la conquista de Gallaecia, Guerra, exploraciones y navegación del mundo antiguo a la edad moderna, 91-100.

Gimeno, E.B. (2011), Análisis de los modos de navegación y estacionamiento de la flota romana: el caso de Iberia durante la Segunda Guerra Púnica, Actas das IV Jornadas de Jovens em Investigação Arqueológica, 93-98.

Gomme, A.W. (1933), A forgotten Factor of Greek Naval Strategy, Journal of Hellenic Studies, $53,16-24$.

Mommsen, T. (1981). Corpus Inscriptionum Latinarum, Vol VII, Inscriptiones Africae Latinae, Berlin.

Reddé, M. (1986). Mare Nostrum. Les infrastructures, le dispositif et l'histoire de la marine militaire sous l'empire romain, Roma.

Torres, C. (1982). La Galicia Romana. Galicia Histórica, Santiago.

Euzennat, M. (1965). Héritage punique et influences gréco-romaines au Maroc á la veille de la conquete romaine, Paris.

Fieliger. Classis, RE, III, col. 2636.

Frankenstein, S. (1997). Arqueología del colonialismo, El impacto fenicio y griego en el sur de la Península Ibérica. Barcelona.

Gagé, J. (1951), Gadès, l'Inde et les navigations atlantiques dans l'Antiquité, Revue historique, 205, 189-216.

García y Bellido. (1960). Colonia Aelia Augusta Italica, Madrid.

García y Bellido. (1969). Numantia, Zaragoza.

García y Bellido. (1985). La Península Ibérica en los comienzos de su Historia, Madrid.

Hawkes, C.H. (1969), Las relaciones Atlánticas en el mundo tartesico, Tartessos, 185 y ss.

Kienast, D. (1966). Untersuchungen zu den Kriegsfloten der römische Kaiserzeit, Bonn.

López Castro, J.L. (1992). La colonización fenicia en la península ibérica: 100 años de investigación, Almería.

Prieto, A. (1987-88), Un punto oscuro en la invasión romana de las Baleares. La piratería, Habis, 18-19, 271-275.

Roselló, E. y Morales, A. (1990), Estudio arqueozoológico de la ictiofauna recuperada en la calle del Puerto, núm. 10, Huelva, Espacio, tiempo y forma. Serie I, Prehistoria y arqueología, 3, 291-298.

Stylow, A.U. - Atencia, R. - González Fernández, J. - González Román, C. - Pastor, M. -Rodríguez, P. (1998). Corpus Inscriptionum Latinorum, Vol II: Inscriptiones Hispaniae Latinae. Pars XIV: Pars meridionales, Conventus tarraconensis, Berlin, Nueva York.

Thouvenot, R. (1939), Statuette d'ivoire trouvée á Volubilis, BSGAOrán, 60, 20-28.

\section{FUENTES CLÁSICAS}

Apiano, (1985), Historia romana, Madrid, Gredos.

Estrabón, (2001-2014), Geografía, Obra Completa, Madrid, Gredos.

César, (2005), Guerra Civil; Guerra de Alejandría; Guerra de África, Guerra de España, Madrid, Gredos.

Filón de Alejandría, (2009-2012), Legatio ad Gaium, Obras completas. Edición de José Pablo Martín, Madrid, Ed. Trotta.

Flavio Josefo, (1997-1999), La guerra de los judíos, Madrid, Gredos.

Floro, (2000), Epítome de la historia de Tito 
Livio, Madrid, Gredos.

Plutarco, (2007), Vidas Paralelas, Madrid, Gredos.

Plinio el Viejo, (1995-2010), Historia natural, Obra completa, Madrid, Gredos.

Plinio el Joven, (2007), Epistolario, Libros I-IX, Madrid.
Suetonio, (1992), Vida de los doce cesares, Obra completa, Madrid, Gredos.

Tácito, (1986), Anales, Obra completa, Madrid, Gredos.

Tito Livio, (1994-1997), Historia de Roma desde su fundación, Obra completa, Madrid, Gredos. 